\title{
Study of the effect of Aliette on the activity of spinach (Spinacea oleracea L.) chloroplasts
}

\author{
Pedro Almeida, João P. Coutinho, João Rocha and José Gomes-Laranjo*
}

Centro de Estudos Tecnológicos, do Ambiente e da Vida, Universidade Trás-os-Montes e Alto Douro, 5000-911 Vila Real, Portugal. *Corresponding author: jlaranjo@utad.pt

Received: 03 January 2007; Returned for revision: 14 April 2007; Accepted: 22 June 2007

Intensification of production in modern agriculture is frequently obtained thanks to the increase of pesticide applications and chemical fertilizers. However, the use of these products sometimes causes a reduction of crop productivity. We aimed to evaluate the impact of the fungicide Aliette on in vitro activity of chloroplasts of spinach (Spinacea oleracea L.). Transmembrane potential formation, PSII oxygen evolution and PSII photochemistry were analyzed. Our results showed that the recommended concentration $\left(2.5 \mathrm{~g} \mathrm{~L}^{-1}\right)$ of Aliette did not impair the photosynthetic apparatus. However, at higher concentrations $\left(>7.5 \mathrm{~g} \mathrm{~L}^{-1}\right)$, reductions in thylakoid membrane potential and oxygen evolution were recorded, but with no evidence of photoinhibition.

Key words: bioenergetics, ecotoxicology, pesticides, photosynthesis, xenobiotics

A intensificação da produção na agricultura moderna é obtida muitas vezes graças ao incremento de aplicações de pesticidas e fertilizantes minerais. No entanto, o uso desses produtos causa, por vezes, a redução da produção. $\mathrm{O}$ objetivo deste estudo foi analisar, in vitro, o efeito do fungicida Aliette sobre a atividade de cloroplastos de espinafre (Spinacea oleracea L.). Os resultados mostraram que a concentração tipicamente recomendada $\left(2,5 \mathrm{~g} \mathrm{~L}^{-1}\right)$ de Aliette não afetou negativamente o aparelho fotossintético. No entanto, a concentrações mais elevadas $\left(>7,5 \mathrm{~g} \mathrm{~L}^{-1}\right)$, registraram-se reduções no potencial de membrana dos tilacóides e na produção de oxigênio, porém sem evidência de fotoinibição.

Palavras-chave: bioenergética, ecotoxicologia, fotossíntese, pesticidas, xenobióticos

With the tremendous development of agriculture after the end of World War II, the expression "Modern Agriculture" was developed, as opposed to the concept of "Traditional Agriculture". Before the war this was the only type of agriculture practised. This new kind of agriculture brought the need for larger areas, of heavy machines and the use of chemical products, with the ability to control the development of some organisms considered as infectants (Wolff, 2005), sometimes disrespecting environmental rules. However, such chemicals can cause severe environmental problems, since they are often used at concentrations higher than those recommended, out of season or in cultures for which they were not originally developed, not to mention the use of forbidden products. In fact, such chemicals interact with organisms other than those for which they were targeted, as well as humans (directly or indirectly), thus constituting a public health problem. Even when recommended concentrations are used, there is always a risk factor. Normally, recommended concentrations are at the limit supported by plants and the environment because the manufacturers of these products cannot run the risk of failing to control these organisms. But what exactly is the impact in terms of photosynthetic productivity for plants?

Aliette Flash belongs to the chemical group of aluminium organometals, with fosetyl aluminium as the active ingredient, whose chemical formula is $\mathrm{C}_{3} \mathrm{H}_{7} \mathrm{O}_{3} \mathrm{Al}$ (Agro Bayer, 2005). Aliette is a bidirectional systemic fungicide (Brown, 2004), which acts directly on fungi, 
stopping the growth of mycelia, reducing the production of spores and reinforcing the natural defences of the plant (Agro Bayer, 2005). This product has no toxicological classification but the dose of $2.5 \mathrm{~g} \mathrm{~L}^{-1}$ applied on foliage is recommended against fungi like Phythium and Phytophthora that affect several crops, such as citrus, lettuce and hop (Orme and Kegley, 2006), It is also used for chestnut to limit ink disease impact caused by Phytophthora cinnamomi (Guest et al., 1989). Chestnut cultivation has experienced a large expansion in Trás-os-Montes (Portugal) which represents almost $80 \%$ of Portugal's total area used for this crop.

The purpose of this research was to study the effect of Aliette Flash on overall activity of the electron transfer chain in spinach chloroplasts (typically the plant model for such studies), together with a more detailed study at the PSII level, namely using the chlorophyll fluorescence methodology, which is a sensitive phytotoxic indicator (Seery et al., 2006), the rate of oxygen evolution and PSII functioning at the electron donor side.

All experiments were carried out at $25^{\circ} \mathrm{C}$. Thylakoid isolation was carried out according to the basic procedure described by Gomes-Laranjo et al. (2005) for spinach. The concentration of photosynthetic pigments was calculated following the equations of Lichtenthaler (1987). Changes in thylakoid membrane potential $(\Delta \Psi)$ were observed with a fluorescent cationic probe 9-amino6-chloro-2-methoxyacridine (ACMA), according to Gomes-Laranjo et al. (2005, 2006). In the control assay, 10 $\mu \mathrm{M}$ of ACMA were added after 2 min to $25 \mathrm{~g}$ chlorophyll $\mathrm{m}^{-3}, 200 \mathrm{mM}$ sorbitol, $2 \mathrm{mM}$ tricine- $\mathrm{NaOH}$ (pH 8.4), $4 \mathrm{mM}$ $\mathrm{MgCl}_{2}, 150 \mathrm{mM} \mathrm{KCl}$, and $30 \mathrm{mM}$ methyl viologen. After 5 min, the chloroplasts were excited with red radiation (>600 nm, $250 \mathrm{~mW} \mathrm{~cm}^{-2}$ ), provided from below, for $4 \mathrm{~min}$. In the assays with Aliette, the only difference was that before the addition of ACMA, Aliette was added in vitro giving a final concentration between 2.5 and $20 \mathrm{~g} \mathrm{~L}^{-1}$. Oxygen evolution was simultaneously measured polarographically using a Clark-type oxygen electrode (Carpentier et al., 1984).

Chlorophyll $a$ fluorescence was monitored with an FMS1 fluorometer (Hansatech, Norfolk, UK). The reaction medium was the same as that used in the studies with ACMA. Measurements were made of basal fluorescence $\left(\mathrm{F}_{0}\right)$, maximal fluorescence $\left(\mathrm{F}_{\mathrm{m}}\right)$ under saturating light pulse (18000 $\left.\mu \mathrm{mol} \mathrm{m} \mathrm{m}^{-2} \mathrm{~s}^{-1}\right)$, steady-state fluorescence $\left(\mathrm{F}_{\mathrm{s}}\right)$ at actinic radiation $\left(300 \mu \mathrm{mol} \mathrm{m} \mathrm{m}^{-2} \mathrm{~s}^{-1}\right)$ and maximal fluorescence with reaction centres partially closed $\left(\mathrm{F}_{\mathrm{m}}{ }^{\prime}\right)$ (Figure 1). From these parameters, $\mathrm{F}_{\mathrm{v}} / \mathrm{F}_{\mathrm{m}}$ (variable-to-maximal fluorescence ratio, which represents the maximal photochemical efficiency of PSII), $\Phi_{\text {PSII }}$ (quantum yield of PSII electron transport), $q_{p}$ (photochemical quenching coefficient) and $\mathrm{q}_{\mathrm{NP}}$ (nonphotochemical quenching coefficient) were calculated according to Laisk and Oja (1998). All results presented here were from a single assay, but similar results were obtained in three independent experiments. Analyses of data were carried out using the Microsoft Excel program in order to obtain the second-degree polynomial regression models.

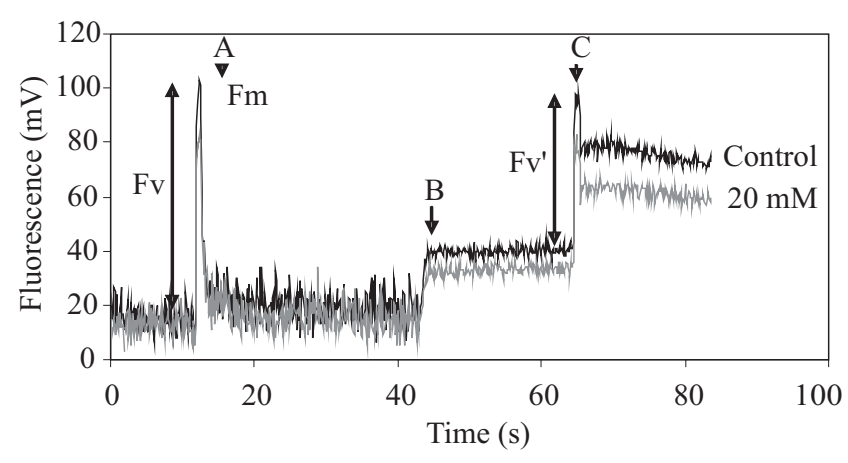

Figure 1. Typical trace of chlorophyll fluorescence obtained with free xenobiotic spinach chloroplast extract and after application of $20 \mathrm{mM}$ Aliette. Basal $\left(\mathrm{F}_{0}\right)$, maximal $\left(\mathrm{F}_{\mathrm{m}}\right)$ and variable $\left(\mathrm{F}_{\mathrm{v}}\right)$ fluorescence were determined in darkadapted samples (open PSII reaction centres); $\mathrm{F}_{\mathrm{m}}$ was obtained after an actinic light pulse (A). In light-adapted samples, steady-state $\left(\mathrm{F}_{\mathrm{s}}\right)$, maximal $\left(\mathrm{F}_{\mathrm{m}}{ }^{\prime}\right)$ and variable $\left(\mathrm{F}_{\mathrm{v}}{ }^{\prime}\right)$ fluorescence were measured under dim light (after B) conditions with partially open PSII reaction centres and after a new actinic light pulse (C).

It should be noted that the recommended Aliette concentration to be applied on foliage is $2.5 \mathrm{~g} \mathrm{~L}^{-1}$, whereas in this study the fungicide was applied at concentrations ranging from 0 to $20 \mathrm{~g} \mathrm{~L}^{-1}$ directly to a thylakoid suspension. Since only a fraction of Aliette applied on foliage reaches the photosynthetic apparatus, an exacerbation of potential effects of the fungicide on photosynthesis, for a given concentration, is to be expected in this study in comparison with foliar Aliette applications. In any case, our results showed that Aliette 
applied directly to thylakoid extracts at concentrations up to $3.75 \mathrm{~g} \mathrm{~L}^{-1}$ caused little, if any, inhibition to the membrane potential (Figure 2A). Nevertheless, this pesticide was able to inhibit the potential formation, as could be seen at higher concentrations, e.g. 12.5 and $20 \mathrm{~g}$ $\mathrm{L}^{-1}$, where potential formation was reduced by 15 and $25 \%$, respectively. A strong influence was observed with regard to half-times of extinction $\left(\mathrm{t}_{0,5} \mathrm{l}\right)$ and recovery $\left(\mathrm{t}_{0,5} \mathrm{~d}\right)$ of fluorescence (Figure 2B), which represents the respective times of membrane potential formation when energization is promoted and the dissipation of that potential after stopping their energization (excitation light off). These results suggest that the application of Aliette can alter the potential formation response, as the increase in $\mathrm{t}_{0,5} 1$ from 3 to $8.3 \mathrm{~s}$ occurred between $0 \mathrm{~g} \mathrm{~L}^{-1}$ (control) and $20 \mathrm{~g}$ Aliette $\mathrm{L}^{-1}$. A similar increase was observed for the potential dissipation $\left(t_{0,5} d\right)$ which rose from 9 to $14 \mathrm{~s}$ over the same treatment range. In fact, at the recommended Aliette concentration for application on plants, $\mathrm{t}_{0,5} \mathrm{l}$ and $\mathrm{t}_{0,5} \mathrm{~d}$ increased 50 and $17 \%$, respectively.

Oxygen evolution capacity, under conditions of energization of thylakoid membranes (Figure 2C) decreased especially at concentrations above $7.5 \mathrm{~g}$ Aliette $\mathrm{L}^{-1}$, although no significant negative effect was found at the recommended concentration. It should be pointed out that at a concentration of $20 \mathrm{~g} \mathrm{~L}^{-1}$, oxygen evolution capacity was reduced to almost $60 \%$ relative to control levels.

Slight changes in chlorophyll $a$ fluorescence parameters in response to Aliette application were observed, but only when chloroplasts were studied under steady-state actinic light conditions, that is, with PSII reaction centres partially reduced (Figure 3). However, in addition to the $\mathrm{F}_{\mathrm{v}} / \mathrm{F}_{\mathrm{m}}$ ratio (measured after a dark period, with reaction centres fully oxidized) (Figure $3 \mathrm{~A}$ ), $\Phi_{\text {PSII }}$ (Figure 3B) and $\mathrm{q}_{\mathrm{p}}$ (Figure 3C), both measured in a stead-state light period, did not respond to the applied treatments. Differences did indeed emerge when $\mathrm{q}_{\mathrm{NP}}$ was analysed (Figure 3D); where it decreased from 0.057 (control) to $0.023\left(7.5 \mathrm{~g} \mathrm{~L}^{-1}\right)$.

The results suggest that the recommended foliage concentrations of Aliette did not cause significant changes in chloroplast photochemistry even when applied directly to a thylakoid extract. However, at higher doses, negative effects are to be expected, as judged by the changes in some of the parameters studied. The
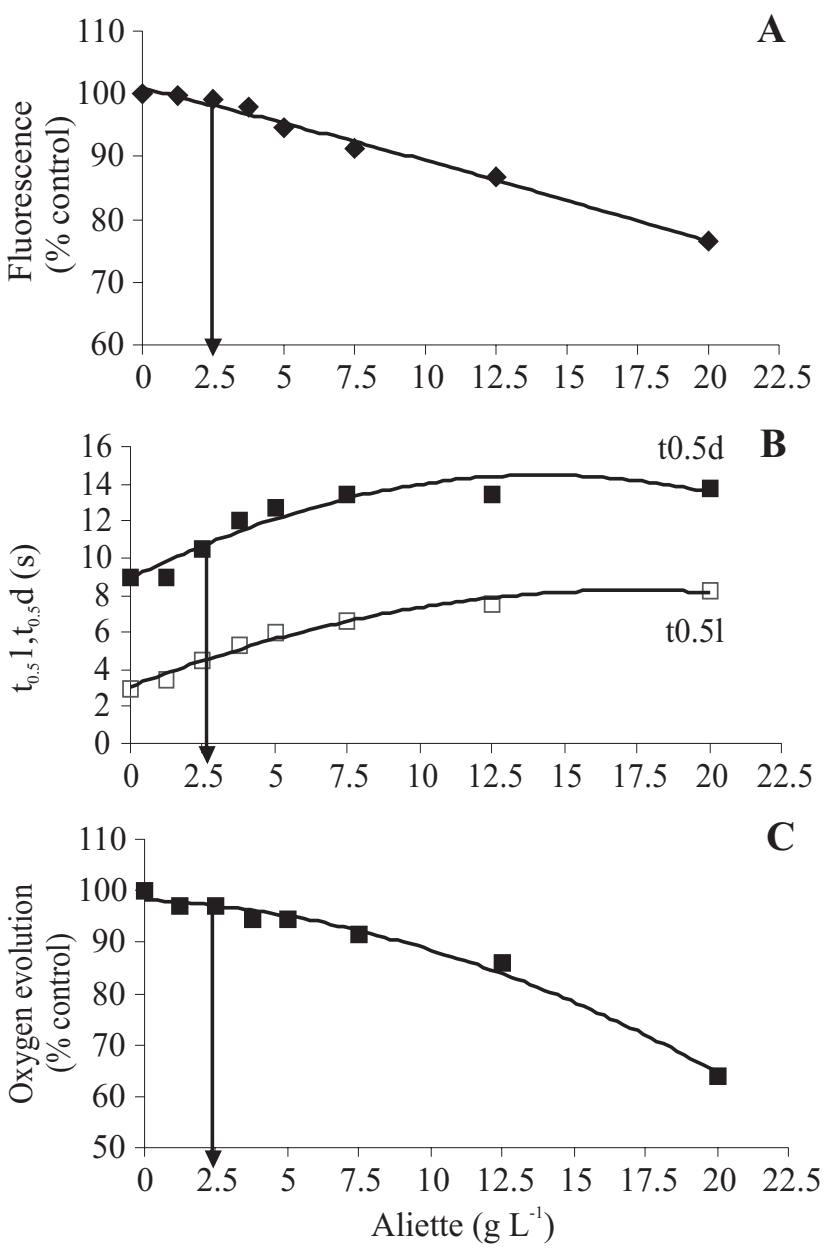

Figure 2. Effect of Aliette on spinach thylakoid membrane potential parameters, measured using the cationic probe 9-amino-6-chloro-2-methoxyacridine: fluorescence quenching of molecular probe (A), half-time of fluorescence quenching $\left(\mathrm{t}_{0,5} 1\right)$ (open symbols) and fluorescence recovery $\left(\mathrm{t}_{0,5} \mathrm{~d}\right)$ (closed symbols) (B), and oxygen evolution measured using a Clark-type oxygen electrode $(\mathbf{C})$. Arrow indicates the recommended concentration of Aliette for application to plants. Results were from a single assay, but similar results were obtained in three independent experiments.

reduction of membrane potential formation capacity (Figure 2) reflects such an impact both with the increase in the time of membrane potential formation and dissipation. Although this is not visible in the amplitude of potential (data not shown), which is similar to that obtained for the recommended concentration, with higher Aliette concentrations a longer time was needed to reach that potential. That could be due to a degradation of the 

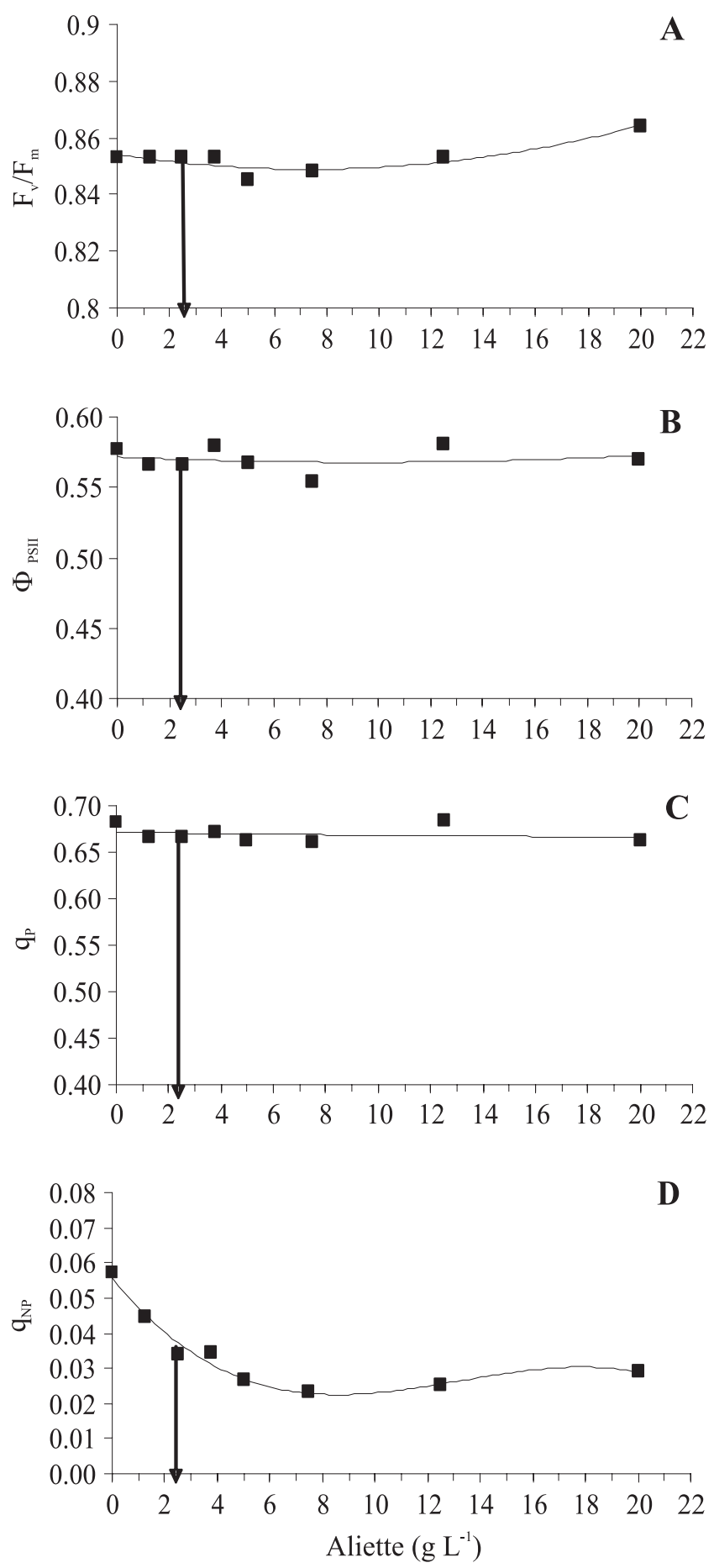

Figure 3. Effect of Aliette at several concentrations on chlorophyll $a$ fluorescence parameters evaluated in spinach chloroplasts: variable-to-maximal dark-adapted fluorescence ratio, $\mathrm{F}_{\mathrm{v}} / \mathrm{F}_{\mathrm{m}}(\mathbf{A})$, quantum yield of PSII electron transport, $\Phi_{\text {PSII }}(\mathbf{B})$, photochemical, $\mathrm{q}_{\mathrm{p}}(\mathbf{C})$ and non-photochemical, $\mathrm{q}_{\mathrm{NP}}$ (D) quenching coefficients. See legend to Figure 2 for other details. thylakoid membrane, which would become permeable allowing the exit of protons previously transferred by electron transport chains to the lumen. Such possible membrane leakage might be due to lipid peroxidation, although an increased time of potential dissipation and potential formation may be related to a lower thylakoid electron transport. On the other hand, the relaxation of intrathylakoid potential in healthy thylakoid membranes is related to the proton movement from lumen to stroma via ATP synthase (Gomes-Laranjo et al., 2006).

Alliete did decrease oxygen evolution when applied to the thylakoid extract at doses above $7.5 \mathrm{~g} \mathrm{~L}^{-1}$. Because oxygen is formed in the OEC complex, we suggest that this structure is affected by fosetyl aluminium and, consequently, the functioning of PSII, the electron transference and the membrane potential formation. Despite this effect and that observed on the membrane potential formation/relaxation, the fluorescence parameters $\mathrm{F}_{\mathrm{v}} / \mathrm{F}_{\mathrm{m}}$ and $\Phi_{\text {PSII }}$ (Figure $3 \mathrm{~A}, \mathrm{~B}$ ) showed negligible changes detected for the range of pesticide concentrations herein employed, suggesting absence of photoinhibitory damages (Krause and Weis, 1988; Correia et al., 2006). In any case, the decreased nonphotochemical quenching (Figure 3D) might be attributed to a diminution in $\mathrm{F}_{\mathrm{m}}$, , since no significant variation was observed in Fv (Figure 1). According to Krause and Weis (1988), this quenching could be due to the diminution of the intrathylakoid acidification caused by electron transport, which was also demonstrated by the reduction of the membrane potential (Figure 2A).

From the above, we conclude that Aliette, at the recommended concentration, does not impair the functioning of the photosynthetic machinery, but at concentrations above that recommended it can negatively impact the bioenergetics of spinach chloroplasts.

\section{REFERENCES}

Agro Bayer (2005) Propriedades Aliette Flash. (Access: http://www.agro.bayer.com.pt)

Brown S (2004) Insensitivity to the fungicide fosetylaluminium in California isolates of the lettuce downy mildew pathogen, Bremia lactucae. Plant Dis. 88:502508.

Carpentier R, Larue B, Leblanc RM (1984) Photoacoustic spectroscopy of Anacystis nidulans. III. Detection of 
photosynthetic activities. Arch. Biochem. Biophys. 228:534-543.

Correia MJ, Osório ML, Osório J, Barrote I, Martins M, David MM (2006) Influence of transient shade periods on the effects of drought on photosynthesis, carbohydrate accumulation and lipid peroxidation in sunflower leaves. Environ. Exp. Bot. 58:75-84.

Gomes-Laranjo JCE, Salgado P, Wong Fong Sang HW, Kraayenhof R, Torres-Pereira J (2005) Isolation of chestnut chloroplasts: Membrane potentials of chestnut and spinach thylakoids. Photosynthetica 43:237-246.

Gomes-Laranjo JCE, Peixoto P, Wong Fong Sang HW, Torres-Pereira J (2006) Study of the temperature effect in three chestnut (Castanea sativa Mill.) cultivars' behaviour. J. Plant Physiol. 163:945-955.

Guest DI, Upton JCR, Rowan KS. (1989) Fosetyl-Al alters the respiratory response in Phytophthora nicotianae var. nicotianae-infected tobacco. Physiol. Mol. Plant Pathol. 34:257-65.

Krause HG, Weis E (1988) The photosynthetic apparatus and chlorophyll fluorescence. An introduction. In: Lichtenthaler HK (eds), Applications of Chlorophyll Fluorescence in Photosynthesis Research, Stress Physiology, Hydrobiology and Remote Sensing, pp.311. Kluwer Academic Publishers, Dordrecht.

Laisk A, Oja V (1998) Techniques in plant science No 1. Dynamics of leaf photosynthesis. Rapid-responses measurements and their interpretations. CSIRO Publishing, Collingwood.

Lichtenthaler HK (1987) Chlorophylls and carotenoids: pigments of photosynthetic biomembranes. Meth. Enzymol. 48:350-382.

Orme S, Kegley S (2006) PAN Pesticide Database. Pesticide Action Network, North America, San Francisco. (Access: http:www.pesticideinfo.org).

Seery CR, Gunthorpe L, Ralph PJ (2006) Herbicide impact on Hormosira banksii gametes measured by fluorescence and germination bioassays. Environ. Poll. 140:43-51.

Wolff LF (2005) Agricultura Ecológica. (Access: http:// www.agrissustentável.com). 